\title{
Qualification Test System for Radiation Detection Devices - QuTeSt
}

\author{
Monika Risse, Peter Clemens, Jeannette Glabian, Olaf Schumann, Theo Koeble, Hermann Friedrich, \\ Wolfram Berky, Marie Charlotte Bornhoeft, Sebastian Chmel \\ Fraunhofer-Institut für Naturwissenschaftlich-Technische Trendanalysen, Germany \\ monika.risse@int.fraunhofer.de
}

\begin{abstract}
Measurement equipment for the detection and identification of radioactive and nuclear $(\mathrm{RN})$ material has a wide application area. The main application aspects are monitoring, search, and identification. A common goal is to gain reliable measurement results. In the past, the only way to assess the performance of a measuring device was to rely on the data given by the manufacturer of the device itself. Reliable test results from an independent third party are more than welcome. These tests can be performed against consensus standards in order to have reproducible test results, independent of the testing location and the performing laboratory. Fraunhofer INT has conceived and built a test environment to perform dynamic and static test measurements using neutron and gamma sources. Tests can be performed in accordance with the IEC and ANSI standards as well as the ITRAP+10 test procedures. This includes qualification tests of truck portal monitors with the dynamic test system. Generally, the effects of one test parameter on other test parameters are not considered in the test procedures. For example, the accuracy of the dose rate may depend on the energy range of the radioactive source used. Besides the overview of the test systems the paper will address restrictions, problems and limitations of the possible qualification measurements as well as potential limitations arising from the given test procedures themselves.
\end{abstract}

Keywords -Qualification tests, RIID, PRD, SPRD, D3S, QuTeSt, Standards, Accuracy tests, Time to alarm tests.

\section{INTRODUCTION}

$\mathrm{I}_{\mathrm{n}}$ $\mathrm{n}$ the field of the detection of nuclear and radioactive material a large variety of measurement systems exists. These are handheld systems, like Radiation Isotope Identifiers (RIID) or Personal Radiation Detectors (PRD), also in the spectroscopically version as SPRD, or stationary systems like portal monitors (RPM). They all have the common requirement to provide reliable results within a short time.

For decision making processes and the assessment of measurement results one needs a reliable statement about the quality of the devices. The quality of the systems shall be determined by performing qualification tests in accordance with existing test methods.

Different international standards for testing exist. The IEC standards from the International Electrotechnical Commission, the ANSI standards from the American National Standards Institute and ITRAP+ 10 standards.

In the "Illicit Trafficking Radiation Assessment Program (ITRAP+10)", initiated by the European Commission, several laboratories were upgraded to be able to carry out these tests. This is where the Fraunhofer INT started to build the QuTeSt facility. Here tests were performed in accordance with the ITRAP+ 10 test procedures see [9] and [10] .

This paper will introduce the QuTeSt facility and give some exemplary results gained with handheld systems. It will also address aspects arising from the different existing standards.

\section{QuTEST}

The QuTeSt consists of two parts: the static test system and the dynamic test system.

\section{A. Static Test System}

The static test system consists of a central cube for placing the sources. The source can be lifted from a shielded position by a compressed air system in front of the device to be tested.

Fig. 1 shows the system with one guide rail system attached and held by lateral guides on the central cube. We have four guide rails which can each be placed on the sides of the cube or can be placed in a row in order to enlarge the distance from the source. The length of each guide rail is $1.5 \mathrm{~m}$.

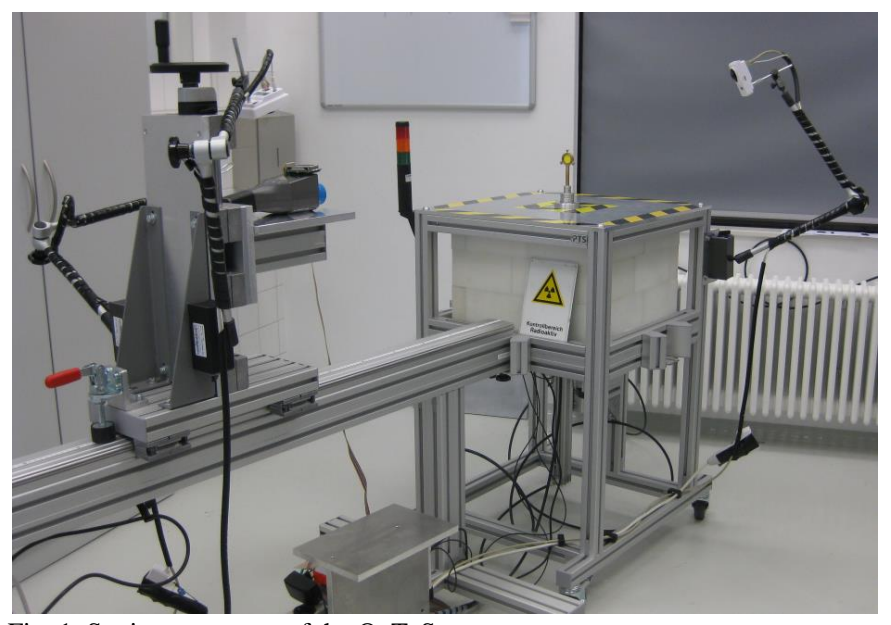

Fig. 1. Static test system of the QuTeSt.

On a roller carriage the device to be tested is placed. Its height can be adjusted which enables us to bring the center of 
the detectors to the same height as the center of the source. The roller carriages are fully adjustable via setting wheels. The roller carriages and the guide rails are equipped with scales for measuring distances.

Together with the device to be tested, a timer is placed and observed by a video camera. The picture, as well as a video obtained from the source, is transferred to and stored at a computer with the software Blue Iris for observation and data storage. Fig. 2 shows the screenshot of the timer camera: on the left the timer and on the right the display part of the measurement device D3S from Kromek, which is introduced in section IV. On the timer the line marked with " $U$ " indicates the duration in the upper position after stepping out. The line marked with " $D$ " indicates the time in the down position inside the shielding.

The stepping times are also given, they are below $0.35 \mathrm{~s}$ and a fast step change is possible.

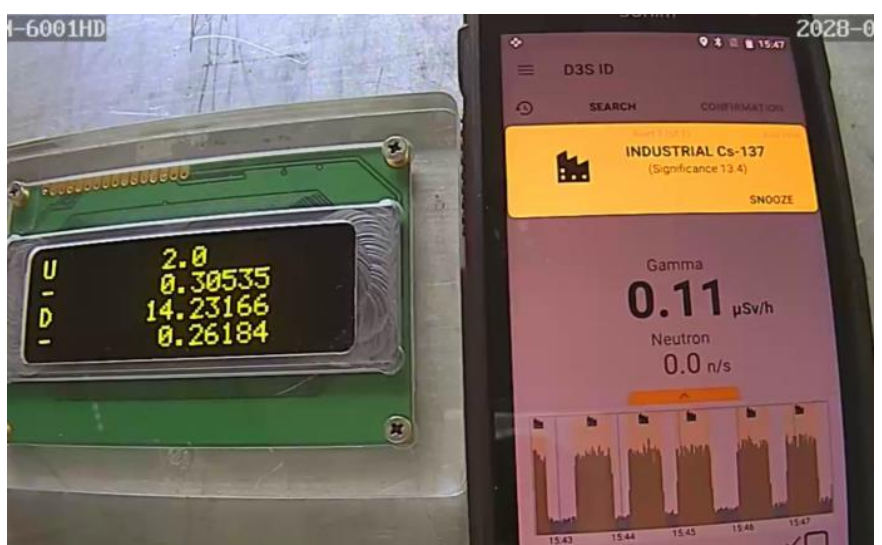

Fig. 2. Exemplarily screenshot of a test. On the left the timer and on the right the display part of the device to be tested, the D3S (see section IV).

\section{B. Dynamic Test System}

Fig. 3 shows the dynamic test system, which consists of a battery powered automated trolley which runs on a rail system mounted on wooden boards. Altogether a track length of $45 \mathrm{~m}$ exists. The velocity can be chosen like needed according to the given standards between $0.02 \mathrm{~m} / \mathrm{s}$ to $2.2 \mathrm{~m} / \mathrm{s}$. Fig. 3 shows the trolley with the source holder in the highest position.

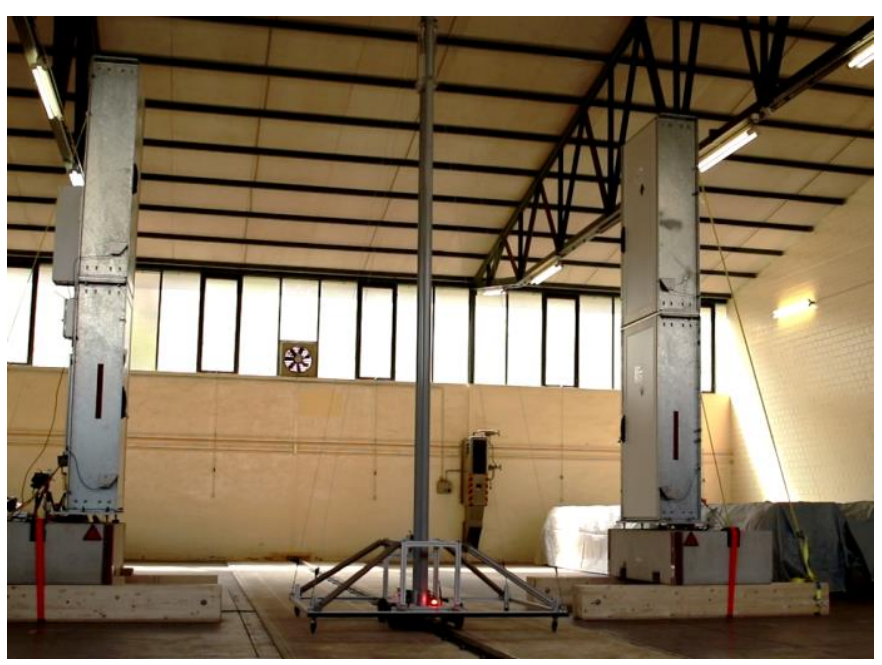

Fig. 3.. Dynamic test system with portal monitor from Arktis.
The same interchangeable source system as for the static system is used and the sources can be placed easily and fast.

The system is portable and can be flexibly set up and operated at any suitable location, as well as adaptions to special needs are possible.

The dynamic system is completed with the video system for observation and documentation of the measurement results and the operating system of the trolley (see Fig. 4).

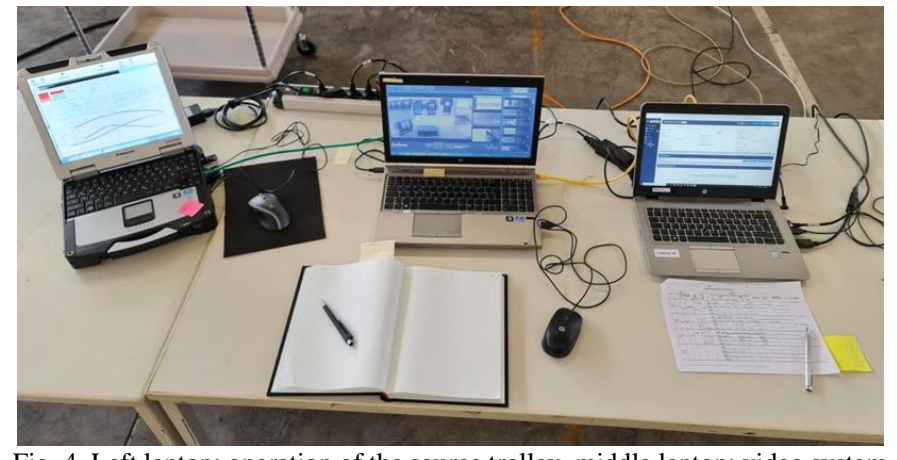

Fig. 4. Left laptop: operation of the source trolley, middle laptop: video system and right laptop: software of the device to be tested.

The left laptop is for operating the source trolley, the middle one for the video system, and if needed we use another one for the test system. For example, for portal monitors the results are displayed on this third laptop and included via HDMI in the video system.

In Fig. 5 an example of a screenshot from a test with handheld devices is given. The source is attached to an extension to get closer to the devices. It is moving as indicated by the direction of the yellow arrow. The display gives the time prior and after passing the zero position which is marked with the red line. The velocity is given as well. Three handheld devices are placed for tests.

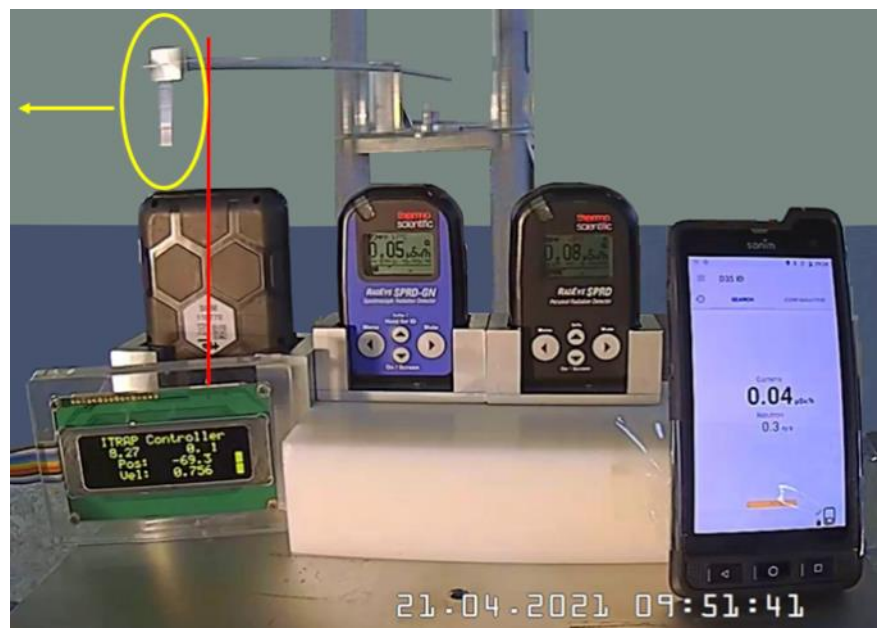

Fig. 5. The source is marked with the yellow ellipse, it is moving in the direction of the yellow arrow. The D3S from Kromek as well as two RadEYE devices from Thermo are tested. Below the source the control display is placed. The red line indicates the zero position.

\section{STANDARD SPECIFICATIONS FOR HANDHELD DEVICES}




\section{A. Time to Alarm Tests for Neutrons}

The specifications for time to alarm tests for neutrons are listed in TableTABLE $I$. All standards state that a ${ }^{252} \mathrm{Cf}$ source with $\mathrm{N}_{\mathrm{R}}=20000 \mathrm{n} / \mathrm{s}$ surrounded by $4 \mathrm{~cm}$ high density polyethylen HDPE shall be used in $\mathrm{d}_{0}=25 \mathrm{~cm}$ distance. The devices shall be placed on a polymethyl methacrylate PMMA phantom.

If the source used does not fulfill the foreseen criterion, the conditions can be changed. With a lower source count rate $N_{T}$, the distance has to be reduced to $d$ using (1). A change in the distance has to be compensated in the dynamic tests by changing the velocity $\mathrm{v}_{0}$ stated in the standard (see Table TABLE I) to $v$ using (2).

$$
\begin{gathered}
d=\mathrm{d}_{0} \times \sqrt{N_{T} / \mathrm{N}_{\mathrm{R}}} \\
v=\mathrm{v}_{0} \times d / \mathrm{d}_{0}
\end{gathered}
$$

In Table I the allowed times to alarm are listed as well as the conditions and the number of trials and the criterion for passing. Three cases foresee a step change test, this is done with the static system. All other cases foresee dynamic tests but partly with the source stopping in front of the device and partly with the source going back and forth. The latter case is for RIID devices with the same conditions for ANSI and IEC. Results we obtained in such a test are given in section V.B

A variety of different test conditions for the time to alarm tests are stated in the common standards. Timing systems are required for the dynamic and the static test systems.

TABLE I

\begin{tabular}{|c|c|c|c|c|c|c|c|c|c|}
\hline \multirow{2}{*}{$\begin{array}{l}\text { Device } \\
\text { class }\end{array}$} & \multicolumn{3}{|c|}{ ANSI } & \multicolumn{3}{|c|}{ IEC } & \multicolumn{3}{|c|}{ ITRAP +10 } \\
\hline & [s] & $\begin{array}{c}\text { condi- } \\
\text { tions }\end{array}$ & trials & {$[\mathrm{S}]$} & $\begin{array}{c}\text { condi- } \\
\text { tions }\end{array}$ & trials & [S] & $\begin{array}{c}\text { condi- } \\
\text { tions }\end{array}$ & trials \\
\hline RIID & 1 & $\begin{array}{l}0.5 \mathrm{~m} / \mathrm{s} \\
\text { passing }\end{array}$ & $9 / 10$ & 2 & $\begin{array}{l}0.5 \mathrm{~m} / \mathrm{s} \\
\text { passing }\end{array}$ & $9 / 10$ & 5 & $\begin{array}{c}\text { step } \\
\text { change }\end{array}$ & $29 / 30$ \\
\hline PRD & 5 & $\begin{array}{c}1.2 \mathrm{~m} / \mathrm{s} \\
\text { source } \\
\text { stops }\end{array}$ & $19 / 20$ & 5 & $\begin{array}{c}1.2 \mathrm{~m} / \mathrm{s} \\
\text { source } \\
\text { stops }\end{array}$ & $8 / 10$ & 5 & $\begin{array}{c}\text { step } \\
\text { change }\end{array}$ & $29 / 30$ \\
\hline SPRD & 5 & $\begin{array}{c}1.2 \mathrm{~m} / \mathrm{s} \\
\text { source } \\
\text { stops }\end{array}$ & $19 / 20$ & 20 & $\begin{array}{c}\text { step } \\
\text { change }\end{array}$ & $8 / 10$ & - & - & \\
\hline
\end{tabular}

TIME TO ALARM SPECIFICATIONS FOR NEUTRONS

All test to be performed with ${ }^{252} \mathrm{Cf}, 20000 \mathrm{n} / \mathrm{s}$, surrounded by $4 \mathrm{~cm} \mathrm{HDPE}$, $25 \mathrm{~cm}$ distance. The device shall be on a PMMA phantom.

ANSI values taken from [4], [5] and [6].

IEC values taken from [1], [2] and [3].

ITRAP+10 values taken from [7] and [8].

\section{B. Time to Alarm Tests for Photons with Step Change}

Similar to the time to alarm test for neutrons, only the ITRAP+10 and the IEC method of test for photons for SPRDs foresee a step change. In here a ${ }^{137} \mathrm{Cs}$ source with $0.5 \mu \mathrm{Sv} / \mathrm{h}$ above background shall be brought in front of the device to be tested. The alarm shall occur within $3 \mathrm{~s}$ for the IEC SPRD and the ITRAP+10 RIID test. For the ITRAP+10 PRD test it shall be within $2 \mathrm{~s}$.

\section{Accuracy Tests for Photons}

In TableTABLE II the accuracy and test dose rate values for the three different standards and the different device classes are shown. The allowed accuracy, which is the percentage deviation from the measured gamma dose rate to the dose rate measured with a reference device, is given as well as the dose rate values which shall be used for the tests. The ANSI tests for RIIDs and PRDs only foresee tests with ${ }^{137} \mathrm{Cs}$, in all other cases the whole energy region is covered and in addition tests with ${ }^{241} \mathrm{Am}$ and ${ }^{60} \mathrm{Co}$ have to be done.

It is important, that prior to the tests it has to be decided which standard shall be used as basis for the tests. As the QuTeSt system was started in the ITRAP+10 program, up to now most of the tests have been carried out under that conditions, whereas the system is not limited to that.

The accuracy tests are performed with the static system.

TABLE II

\begin{tabular}{|c|c|c|c|c|c|c|}
\hline \multirow{2}{*}{$\begin{array}{l}\text { Device } \\
\text { class }\end{array}$} & \multicolumn{2}{|c|}{ ANSI } & \multicolumn{2}{|c|}{ IEC } & \multicolumn{2}{|c|}{ ITRAP +10 } \\
\hline & {$[\%]$} & $\begin{array}{l}\text { test DR } \\
\text { values }^{\mathrm{a}}\end{array}$ & [\%] & $\begin{array}{l}\text { test DR } \\
\text { values }^{\mathrm{a}}\end{array}$ & {$[\%]$} & $\begin{array}{l}\text { test } \mathrm{DR} \\
\text { values }^{\mathrm{a}}\end{array}$ \\
\hline RIID & \pm 10 & $\begin{array}{c}1 \mu \mathrm{Sv} / \mathrm{h}- \\
M\end{array}$ & \pm 30 & $\begin{array}{r}1 \mu \mathrm{Sv} / \mathrm{h} \\
10 \mu \mathrm{Sv} / \mathrm{h} \\
70 \% M\end{array}$ & \pm 30 & $\begin{array}{r}0.5 \mu \mathrm{Sv} / \mathrm{h} \\
5 \mu \mathrm{Sv} / \mathrm{h} \\
50 \mu \mathrm{Sv} / \mathrm{h} \\
100 \mu \mathrm{Sv} / \mathrm{h}\end{array}$ \\
\hline PRD & \pm 30 & $\begin{array}{r}4 \mu \mathrm{Sv} / \mathrm{h} \\
10 \mu \mathrm{Sv} / \mathrm{h} \\
16 \mu \mathrm{Sv} / \mathrm{h} \\
70 \% M\end{array}$ & \pm 50 & $\begin{array}{r}1 \mu \mathrm{Sv} / \mathrm{h} \\
10 \mu \mathrm{Sv} / \mathrm{h} \\
50 \% M\end{array}$ & \pm 30 & $\begin{array}{r}0.5 \mu \mathrm{Sv} / \mathrm{h} \\
5 \mu \mathrm{Sv} / \mathrm{h} \\
50 \mu \mathrm{Sv} / \mathrm{h}\end{array}$ \\
\hline SPRD & \pm 30 & $\begin{array}{r}1 \mu \mathrm{Sv} / \mathrm{h} \\
10 \mu \mathrm{Sv} / \mathrm{h} \\
70 \mu \mathrm{Sv} / \mathrm{h} \\
80 \% M\end{array}$ & \pm 50 & $\begin{array}{r}1 \mu \mathrm{Sv} / \mathrm{h} \\
10 \mu \mathrm{Sv} / \mathrm{h} \\
70 \mu \mathrm{Sv} / \mathrm{h} \\
70 \% M\end{array}$ & - & - \\
\hline
\end{tabular}

ACCURACY SPECIFICATIONS FOR PHOTONS FROM STANDARDS

$M$ indicates the maximum dose rate value stated by the manufacturer. ANSI RIID and PRD tests with ${ }^{137} \mathrm{Cs}$, all other with ${ }^{241} \mathrm{Am},{ }^{60} \mathrm{Co}$ and ${ }^{137} \mathrm{Cs}$. ANSI values taken from [4], [5] and [6].

IEC values taken from [1], [2] and [3].

ITRAP+10 values taken from [7] and [8].

${ }^{a}$ Dose rate values at which tests are performed.

\section{TEST SYSTEM D3S}

The device which is used to show the performance of the QuTeSt system is the D3S from Kromek [11]. It is a system which consists of two parts, which are shown in Fig. 5: the detection unit, which can be worn on a belt, and a smartphone for data collection and display. Both are connected via Bluetooth. The detection unit has as detectors a CsI crystal for gamma detection and a Lithium based one for neutron detection. As the unit is rather small it uses a SiPM. The D3S can either function as PRD or as RIID. Therefore, the different criteria for the different device classes have to be considered when testing.

\section{EXAMPLE TESTS}

\section{A. Time to Alarm - Static}

In Fig. 6 results for 30 separate trials for a time to alarm test with the static test system are given. A ${ }^{137} \mathrm{Cs}$ source is brought in front of the D3S detector via a fast step change with $<0.35 \mathrm{~s}$ 
duration. The IEC standard for SPRDs as well as the ITRAP+10 method of test for RIID devices state that the alarm shall be within $3 \mathrm{~s}$, which is fulfilled in all cases and the test is passed. The criterion for the ITRAP+10 PRD states, that the device shall alarm within $2 \mathrm{~s}$, which is not fulfilled.

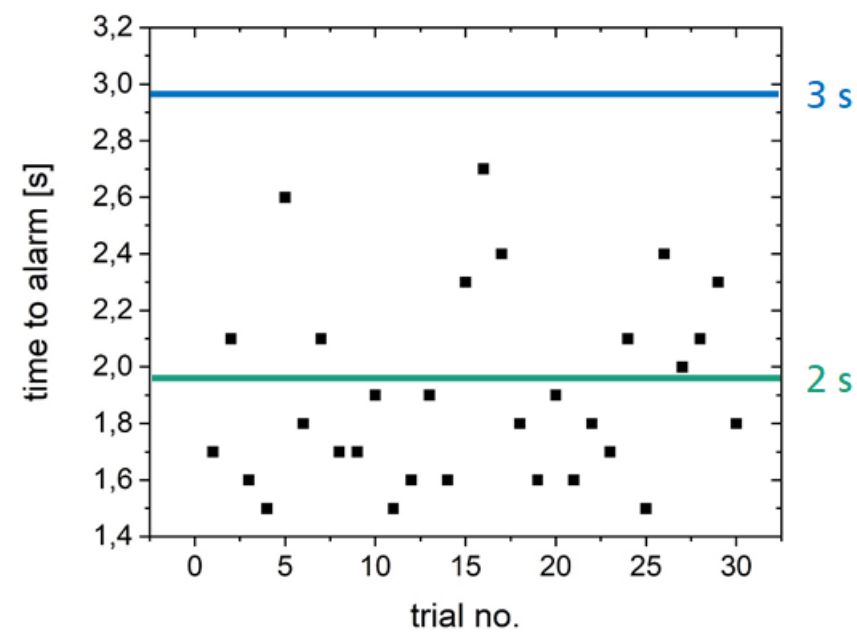

Fig. $6 .{ }^{137} \mathrm{Cs}$ with $0.5 \mu \mathrm{Sv} / \mathrm{h}$ above background brought in front of the D3S via a step change. $3 \mathrm{~s}$ is the criterion for IEC SPRD and ITRAP+10 RIID testing, $2 \mathrm{~s}$ is the criterion for ITRAP+10 PRD testing.

\section{B. Time to Alarm - Dynamic}

Fig. 7 shows the setup of the time to alarm test for neutrons for the D3S. The detector part is fixed to the phantom and the display part is placed next to the display in order to observe the temporal correlation. In this configuration we could not place the HDPE around the source. This is why we placed it in front of the D3S.
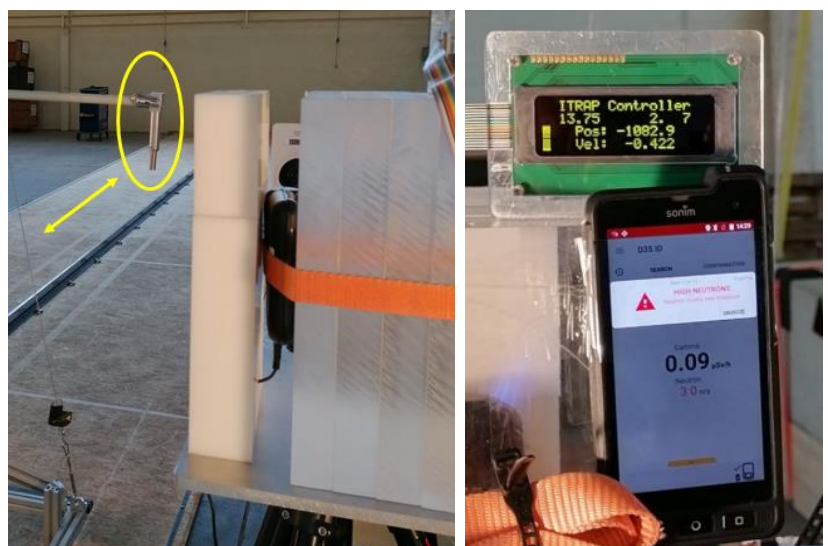

Fig. 7. Left: ${ }^{252} \mathrm{Cf}$ source marked by yellow ellipse is moved. The detector part of the D3S is fixed to the phantom. HDPE is placed in front. Right: The display part of the D3S next to the control display.

Fig. 8 shows the measured time to alarm for 20 trials. The ANSI standard for RIIDs specifies that the alarm shall be no later than $1 \mathrm{~s}$. This happened in only 4 out of 20 cases, which means the device would fail the test. In the case of the IEC standard the alarm shall be within $2 \mathrm{~s}$, which is fulfilled in more cases but still not enough and the device would fail this test, too.

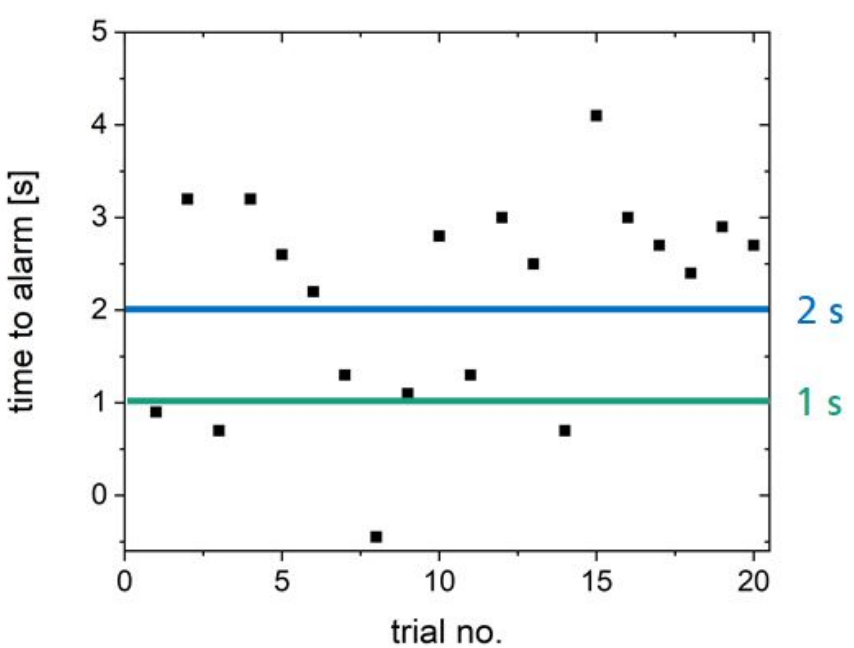

Fig. $8 .{ }^{252} \mathrm{Cf}$ with $14200 \mathrm{n} / \mathrm{s}$ in $20.8 \mathrm{~cm}$ distance and $0.42 \mathrm{~m} / \mathrm{s} .2 \mathrm{~s}$ is the criterion for the IEC test, $1 \mathrm{~s}$ is the criterion for the ANSI RIID test.

\section{Accuracy}

For the accuracy tests, the results of one test are shown exemplarily. As stated in section III.C a large variety of criteria exists. The results for the lowest test point of the ITRAP +10 tests with ${ }^{137} \mathrm{Cs}$, which is $0.5 \mu \mathrm{Sv} / \mathrm{h}$ above the background level, are given in Fig. 9. The values are obtained after stabilization after a step change. The results obtained during 30 individual trials are shown. The value including background is $0.6 \mu \mathrm{Sv} / \mathrm{h}$. The ITRAP +10 gives an accuracy of $\pm 30 \%$, which is clearly fulfilled. Even the $\pm 10 \%$, which is stated for RIIDs in the ANSI Standard, would be fulfilled. This would be the green area in the diagram. But this is only one single criterion from the accuracy tests which does not show the overall performance of the D3S for the accuracy test.

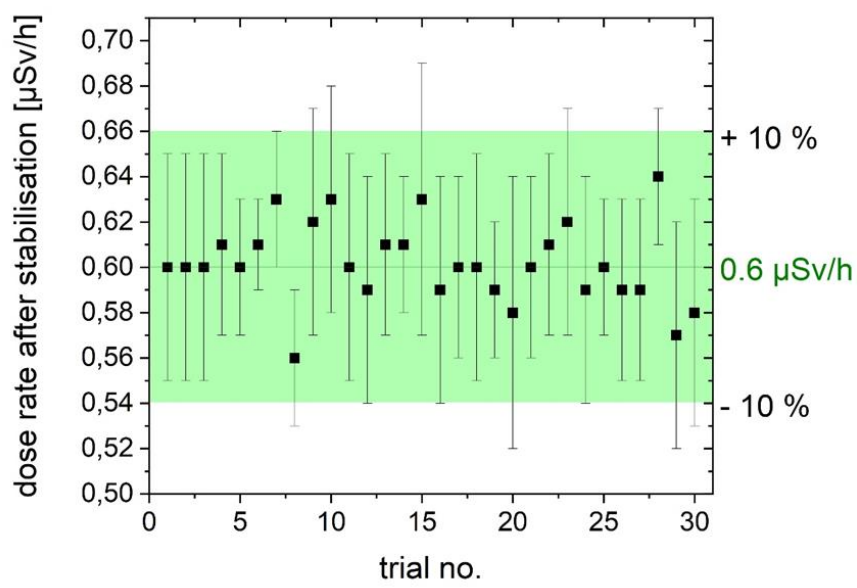

Fig. 9. ${ }^{137} \mathrm{Cs}$ with $0.5 \mu \mathrm{Sv} / \mathrm{h}$ above the background level which is $0.6 \mu \mathrm{Sv} / \mathrm{h}$ brought in front of the D3S after step change. The results obtained during 30 individual trials, i.e. the dose rate values after stabilization, are given.

\section{CONCLUSIONS}

Testing of radiation detection devices can be done according to different standards. We were able to show with the time to alarm tests that accurate time measurement is necessary. A static as well as a dynamic test system is necessary. A good 
observation and documentation system are required, too. Several different radioactive sources are also needed. This is a very important point for testing, which will be addressed in further works.

Our Fraunhofer INT QuTeSt enables us to perform such radiation detection device testing. It is self-made and we can easily adapt it to special needs.

\section{REFERENCES}

Standards:

[1] Radiation Protection Instrumentation - Hand-held Instruments for the Detection and Identification of Radionuclides and for the Estimation of Ambient Dose Equivalent Rate from Photon Radiation, IEC Standard 62327, 2017

[2] Radiation Protection Instrumentation - Alarming Personal Radiation Devices (PRDs) for the Detection of Illicit Trafficking of Radioactive Material, IEC Standard 62401, 2017

[3] Radiation Protection Instrumentation - Spectroscopy-based Alarming Personal Radiation Detectors (SPRD) for the Detection of Illicit Trafficking of Radioactive Material, IEC Standard 62618, 2013

[4] American National Standard Performance Criteria for Handheld Instruments for the Detection and Identification of Radionuclides, ANSI Standard N42.34-2015

[5] American National Standard Performance Criteria for Alarming Personal Radiation Detectors for Homeland Security, ANSI Standard N42.32-2016

[6] American National Standard Performance Requirements for Spectroscopic Personal Radiation Detectors (SPRDs) for Homeland Security, ANSI Standard N42.48-2018

[7] C. Carrapiço, G. Eklund, M. Marin-Ferrer, P. Peerani, F. Rosas, A. Tomanin and H. Tagziria, "Illicit Trafficking Radiation Detection Assessment Program ITRAP+10 Phase II - Round Robin: Radiation Isotope Identifiers Device (RIID) - Test Method", JRC Technical Reports, 2017

[8] C. Carrapiço, G. Eklund, M. Marin-Ferrer, P. Peerani, F. Rosas, A. Tomanin and H. Tagziria, "Illicit Trafficking Radiation Detection Assessment Program ITRAP+10 Phase II - Round Robin: Personal Radiation Detector (PRD) - Test Method”, JRC Technical Reports, 2017

[9] M. Risse, J. Glabian and T. Köble, "Qualification measurements of handheld radiation detectors for homeland security purposes", in INMM 61st Annual Meeting, Virtual Event, 2020, pp. 1172-1181

[10] M. Risse, C. Bornhöft, J. Glabian and T. Köble, "D3S - results of qualification measurements of a wearable RIID for homeland security", in INMM 60th Annual Meeting, Palm Desert, California, USA, 2019, pp. 432-441.

[11] Kromek Limited, "Kromek 3DS ID User Manual," Revision 4.0. [Online] Available: http://www.kromek.com/wp-content/uploads/2019/07/D3SID-User-Manual-A5.pdf. Accessed on: Jun. 30, 2021 